\section{Screening and partial purification of photoprotective pigment scytonemin from cyanobacterial crusts dwelling on the historical monuments in and around Varanasi, India}

\author{
Jainendra Pathak, Arun S. Sonker, \\ Richa, Rajneesh, Vinod K. Kannaujiya, \\ Vidya Singh, Haseen Ahmed, \\ Rajeshwar P. Sinha \\ Laboratory of Photobiology and \\ Molecular Microbiology, Center of \\ Advanced Study in Botany, \\ Institute of Science, Banaras Hindu \\ University, Varanasi, India
}

\begin{abstract}
In the present investigation, biological crusts from the surface of eight historical monuments of Varanasi, India, were examined for the presence of scytonemin (a cyanobacterial photoprotective pigment) containing cyanobacterial species. Lyngbya sp. and Scytonema sp. were the dominant cyanobacteria present in all crust samples. The absorption spectroscopic data of chlorophyll, carotenoids and scytonemin showed that scytonemin was more abundant than the carotene and chlorophyll in all the crusts. Identification of these compounds was done using UV-Vis spectroscopy and High Performance Liquid Chromatography (HPLC) analysis. HPLC analysis revealed the presence of scytonemin in seven out of eight samples and peaks of scytonemin with retention time ranging from 1.4-1.9 min with corresponding absorbance maxima at 386,300 and $252 \pm 2 \mathrm{~nm}$. As per our knowledge this is the first report of its kind from monuments of Varanasi. From this study, it can be concluded that synthesis of photoprotective compounds like scytonemin and its derivatives counteract the damaging effects of solar radiation which enable cyanobacteria to colonize and inhabit almost all kinds of habitats, including extreme lithic habitats, such as rocks and walls of monuments which face prolonged high intensity solar radiation.
\end{abstract}

\section{Introduction}

Ozone depletion has resulted in an increase in the solar ultraviolet radiation (UVR; 280-400 nm) on the Earth's surface which may cause numerous deleterious effects on living organisms hence effecting existence and survival of all organisms. ${ }^{1}$ Absorption of solar radiation to perform photosynthesis and nitrogen fixation exposes cyanobacteria to lethal UVR. ${ }^{2}$ The highenergetic UV-B radiation constitute $<1 \%$ of the total solar irradiance. It affects normal states of life either through direct effects on cellular nucleic acids (denaturation of DNA and RNA) or indirectly by the production of reactive oxygen species (ROS) ${ }^{3,4}$ in various living systems including phytoplankton, ${ }^{5}$ bacteria $^{6}$ and cyanobacteria. ${ }^{7}$ In contrast, UV-A (315-400 $\mathrm{nm})$ radiation is not absorbed directly by the native DNA, but still induce DNA damage either by producing a secondary photoreaction of existing DNA photoproducts or via indirect photosensitizing reactions. ${ }^{8,9}$ Several defense strategies have been evolved in cyanobacteria to counteract the damaging effects of UV, such as migration, mat formation, synthesis of antioxidants, presence of specific active repair mechanisms and UV-absorbing compounds. ${ }^{10,11}$ The UV-absorbing/ screening compounds such as mycosporine-like amino acids (MAAs) ${ }^{12}$ and scytonemin have received fair attention for their potential role in UV photoprotection. ${ }^{13}$ Scytonemin, a dimer of indolic and phenolic subunits, is a yellow-brown lipid soluble pigment located in the extracellular polysaccharide sheath of about 300 cyanobacterial species. Purified scytonemin has maximum UV absorption at $384 \pm 2 \mathrm{~nm}$, although it may also absorb significantly at 252, 278 and $300 \mathrm{~nm} .{ }^{14}$ The main peak of scytonemin lies in the UV-C region, but the additional peaks in the UV-B and UV-A regions are protective against UV radiation which is important in the current atmosphere which lacks UV-C. Scytonemin exists in oxidized (Mw $544 \mathrm{Da})$ as well as reduced $(\mathrm{Mw} 546 \mathrm{Da})$ form depending on the redox and acid-base conditions during the process of extraction. ${ }^{15}$ Metabolites of aromatic amino acid biosynthesis are thought to be precursors of scytonemin biosynthesis, which can be induced by high photon fluence rate. ${ }^{15}$ Scytonemin is highly stable against different stresses and performs its UV-absorbing/screening activity without any further metabolic investment. ${ }^{16}$ The UV-sunscreen role of scytonemin has been well demonstrated in the terrestrial cyanobacteria. ${ }^{17}$ Scytonemin prevent cellular damage by acting as an antioxidant against UV-induced production of ROS. ${ }^{13,18}$ Because of its potential UVabsorbing/screening capacity as well as nontoxic and antiproliferative properties, ${ }^{19,20}$ scytonemin may be biotechnologically exploited for pharmaceutical and cosmetic applications. ${ }^{21}$ Hence, the main objective of this study was to explore the scytonemin
Correspondence: Rajeshwar P. Sinha, Laboratory of Photobiology and Molecular Microbiology, Center of Advanced Study in Botany, Institute of Science, Banaras Hindu University, Varanasi 221005, India.

Tel.: +91.542.2307147 - Fax: +91.542.2366402. E-mail: r.p.sinha@gmx.net; rpsinhabhu@ gmail.com

Key words: Cyanobacteria; Photoprotection; Scytonemin; Solar radiation; High performance liquid chromatography.

Acknowledgements: this work was supported by Council of Scientific and Industrial Research, New Delhi, India, under grant (09/013/0515/2013-EMR-I), (09/013/0258/ 2009-EMR-I) and (09/013(0568)/2014-EMRI) awarded to J. Pathak, V.K. Kannaujiya and V. Singh respectively. This work was also supported by Department of Science and Technology sponsored project (No. SR/WOSA/LS-140/2011) sanctioned to Richa. A.S. Sonker and $\mathrm{H}$. Ahmed are thankful to University Grants Commission, New Delhi, India, for the fellowship under grant (UGCJRF-276/S-01) and (UGC-JRF- 21-12-2014 (ii) EU-V) respectively. Rajneesh is thankful to Department of Biotechnology, Govt. of India, for the fellowship (DBT$\mathrm{JRF} / 13 / \mathrm{AL} / 143 / 2158$ ).

Contributions: JP, designed, performed the experiments and wrote the manuscript; ASS, helped during collection of samples and performing the experiments; Ra, helped in performing experiments and drafting the paper; VKK, VS, HA, helped in performing experiments; Ri, evaluated the data and edited the manuscript; RPS, generated the idea, designed the study and wrote the paper.

Conflict of interest: the authors declare no potential conflict of interest.

Received for publication: 10 May 2016 Revision received: 11 August 2016.

Accepted for publication: 18 August 2016

This work is licensed under a Creative Commons Attribution NonCommercial 4.0 License (CC BY-NC 4.0).

CC Copyright J. Pathak et al., 2017

Licensee PAGEPress, Italy

Microbiology Research 2017; 8:6559

doi:10.4081/mr.2017.6559

containing cyanobacteria inhabiting historical monuments of Varanasi, India and screening and partial purification of photoprotective compound, scytonemin from cyanobacterial samples collected from eight historical monuments of the holy city of Varanasi, India 


\section{Materials and Methods}

\section{Collection site and sample collection}

Varanasi is situated between the $25^{\circ} 28^{\prime}$ North, $82^{\circ} 96^{\prime}$ East, in the eastern part of Uttar Pradesh, India. Samples were taken aseptically from eight different sites namely Brahaspati Temple, Ramnagar Fort, Vishwanath Temple, BHU, Sanskrit University's old building, Madhavrav's Dharhara, Brahaspati Temple, Jalnigam's old tank and Dhamek Stupa, Sarnath (Figure 1). These are very popular monuments of Varanasi having great historical and religious importance and many of these monuments are included as protected monuments of Archaeological Survey of India. Since these monuments are protected by Archaeological Survey of India, nondestructive sampling techniques were used to collect the crusts from the surfaces with a sterile plastic scalpel. Samples were immediately placed into a sterile plastic bag and transported to the laboratory for analyses. Digital images and coordinates of sampling sites were recorded using a digital camera and GPS respectively. Light intensity, UVA, UV-B radiation, temperature and relative humidity at sites was recorded with a lux meter, solarmeter, digital thermometer and hygrometer respectively. All the experiments were repeated thrice with at least three replicates and the mean values $\pm \mathrm{SD}$ were calculated from three replicates $(n=3)$.

\section{Identification of organisms}

The collected crusts were soaked with sterile distilled water for $2 \mathrm{~h}$ and cleaned repeatedly with sterile distilled water. To examine the presence of algae in the crust, a pinch of the rehydrated crust was observed in compound microscope. The organisms appearing in the crusts were further exam- ined using Image binocular microscope and photographed using Dewinter-2011 scientific digital camera and analyzed with Dewinter software. The organisms belonging to cyanobacteria were identified following standard monographs. ${ }^{22}$

\section{Pigment analysis}

Pigment profile of crust was analyzed taking equal amount of crust (5 mg) from each monument, extracted in $90 \%$ methanol (v/v) and the absorption spectra were measured in a Hitachi U-2190 UVVisible double beam spectrophotometer in the wavelength range of 200-800 nm using quartz cuvettes. Quantity of chlorophyll - a was estimated using the extinction coefficient of Mackinney (1941) $)^{23}$ and Dere et al. $(1998)^{24}$ and the amount of total carotenoids was determined following Davis $(1976)^{25}$

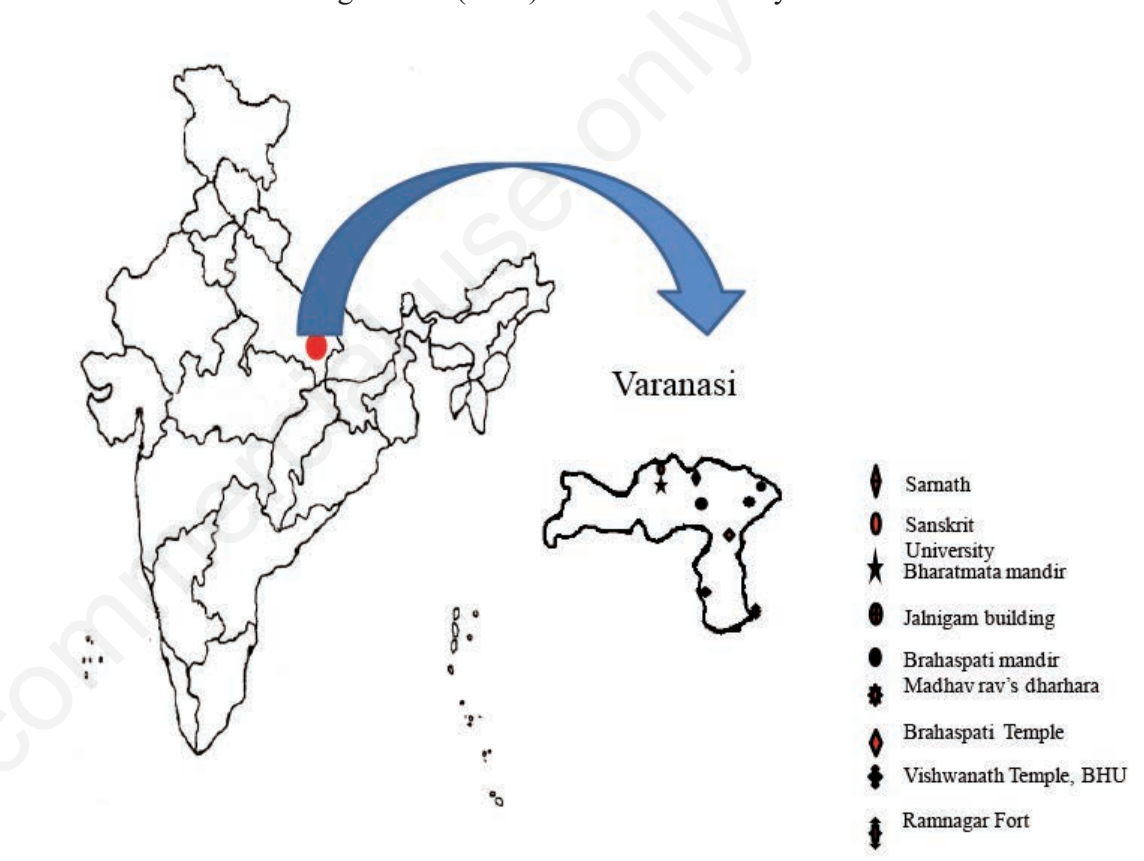

Figure 1. Cyanobacterial crust collection sites of Varanasi, India. tonemin content was calculated using the trichromatic equation following GraciaPichel and Castenholz (1991) ${ }^{15}$ from $10 \mathrm{mg}$ dry weight of crusts.

\section{Extraction of scytonemin}

From crusts scytonemin was extracted in $1: 1(\mathrm{v} / \mathrm{v})$ methanol:ethyl acetate by overnight incubation at $4{ }^{\circ} \mathrm{C}$ followed by sonication (2011-Sonic, cycle $30 \%$, Power $40 \%$ ) for $4 \mathrm{~min}$. After centrifugation $(10,000 \mathrm{~g}$ for $5 \mathrm{~min})$, supernatants were evaporated in a vacuum evaporator at $38^{\circ} \mathrm{C}$ and redissolved in $500 \mu \mathrm{L}$ of $1: 1(\mathrm{v} / \mathrm{v})$ methanol:ethyl acetate. Subsequently, the samples were filtered through $0.22 \mu \mathrm{m}$ pore-sized sterilized microcentrifuge syringe-driven filter before being subjected to HPLC analysis. and Dere et al. (1998). ${ }^{24}$ The cellular scy-

Table 1. Cyanobacteria colonizing surface of different historical monuments of Varanasi, India.

\begin{tabular}{|c|c|c|c|c|c|c|c|c|}
\hline Organisms & Ramnagar Fort & $\begin{array}{c}\text { Bharatmata } \\
\text { Temple }\end{array}$ & $\begin{array}{c}\text { Brahaspati } \\
\text { Temple }\end{array}$ & $\begin{array}{c}\text { Monuments } \\
\text { Vishwanath } \\
\text { Temple }\end{array}$ & $\begin{array}{c}\text { Madhavrav's } \\
\text { dharhara }\end{array}$ & $\begin{array}{l}\text { Sanskrit } \\
\text { university }\end{array}$ & Jalnigam & $\begin{array}{l}\text { Dhamek } \\
\text { Stupa, } \\
\text { Sarnath }\end{array}$ \\
\hline Lyngbya sp. & + & - & - & + & + & + & + & - \\
\hline Nostoc commune & + & - & - & - & - & + & - & + \\
\hline Nostoc sp. & + & - & + & - & - & + & - & - \\
\hline Anabaena sp. & + & & + & 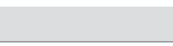 & + & & & + \\
\hline Scytonema sp. & - & + & + & + & - & + & + & - \\
\hline Phormidium sp. & + & - & - & - & - & - & - & - \\
\hline Aulosira sp. & - & - & + & - & - & - & - & + \\
\hline Westiellopsis sp. & - & - & + & - & - & - & - & - \\
\hline Aphanocapsa sp. & - & - & - & + & - & - & - & - \\
\hline Aphanothece sp. & - & - & - & + & - & - & - & - \\
\hline
\end{tabular}




\section{High Performance Liquid}

\section{Chromatography analysis}

Partially purified scytonemin was analysed using a HPLC system (Waters 2998, Photodiode Array, pump L-7100, USA) equipped with a Licrospher RP 18 column and guard (5 $\mu \mathrm{m}$ packing; $250 \mathrm{~mm} \times 4 \mathrm{~mm}$ inside diameter). The samples (10 $\mu \mathrm{L})$ were injected into the HPLC column through an auto-injector into the HPLC column through a Waters 717 plus autosampler. Elution was at a flow rate of $1.0 \mathrm{~mL} \mathrm{~min}-1$ using the mobile phase of solvent A (ultra pure water) and solvent B (acetonitrilemethanol-tetrahydrofuran, 75:15:10, v/v). The 30 min gradient elution programme was set with 0-15 min linear increase from $15 \%$ solvent A to $100 \%$ solvent $\mathrm{B}$, and 15 30 min at $100 \%$ solvent $\mathrm{B}$. The detection wavelength was at $376 \mathrm{~nm}$. PDA scan wavelength was from 250 to $750 \mathrm{~nm}$. Scytonemin was identified by its characteristic absorption maxima in the solvent corresponding to the appropriate retention time. ${ }^{15,26,27}$

\section{Results}

\section{Nature of the crust and algal identi-} fication

The nature of crusts in all the eight monuments were greenish to brown in colour, predominately growing in the crevices, roof tops and portions which were exposed to high solar and UV radiation (Figure 2). Varanasi experiences a humid subtropical climate with large variations between summer and winter temperatures. The dry summer starts in April and lasts until June, followed by the monsoon season from July to October. The temperature ranges between 22 and $46^{\circ} \mathrm{C}\left(72\right.$ and $\left.115^{\circ} \mathrm{F}\right)$ in the summers. The average annual rainfall is $1,110 \mathrm{~mm}$ (44 in). There was no significant variation in the climatic conditions of the eight monuments and the environmental data in summer months shows light intensity varies from 41.56 to $45.34 \mathrm{w} / \mathrm{m}^{2}$, UV-A 3.99 to 4.10 $\mathrm{mw} / \mathrm{cm}^{2}$, UV-B 0.43 to $0.47 \mathrm{mw} / \mathrm{cm}^{2}$, temperature $44-50^{\circ} \mathrm{C}$ and relative humidity $81-$ $85 \%$. Ten species of cyanobacteria were reported from the crust samples of eight monuments of Varanasi (Table 1). Among the algal group, cyanobacteria were the dominant population growing in all the monuments. Out of all the crust samples examined for the presence of algae, Lyngbya sp. and Scytonema sp. were the major taxa in all the monuments (Figure 3). In all the crusts samples sheathed filamentous cyanobacteria were in abundance. Species composition of the crusts varied with the amount of solar
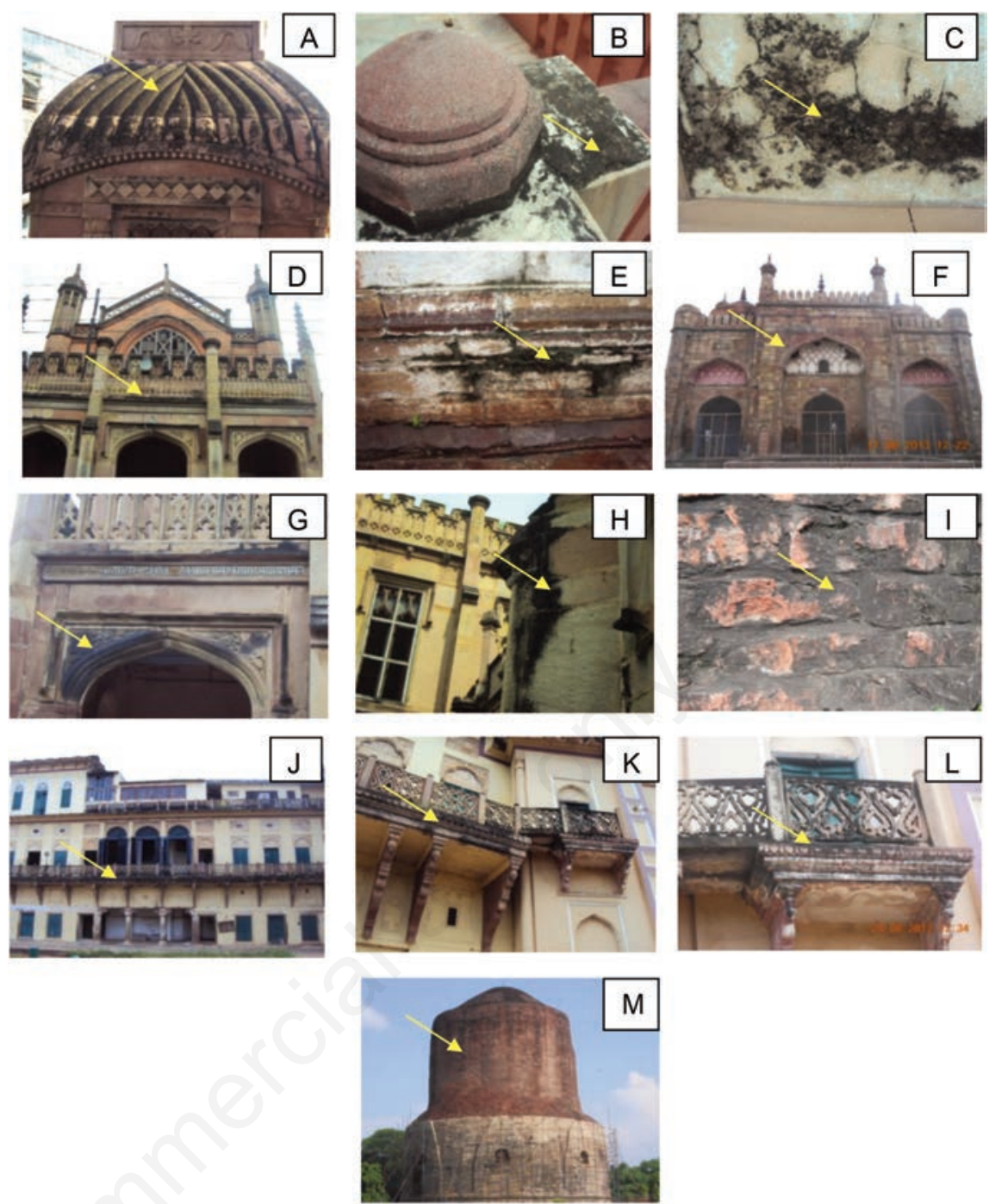

Figure 2. Historical monuments of Varanasi, India, showing surface colonization of cyanobacteria. (A) Brahaspati Temple, (B) Vishwanath Temple, BHU, (C) Bharatmata Temple, (D, E) Madhavrav's Dharhara, (F-H) Sanskrit University, (I) Jalnigam's old tank, (J-L) Ramnagar Fort and (M) Dhamek Stupa, Sarnath.
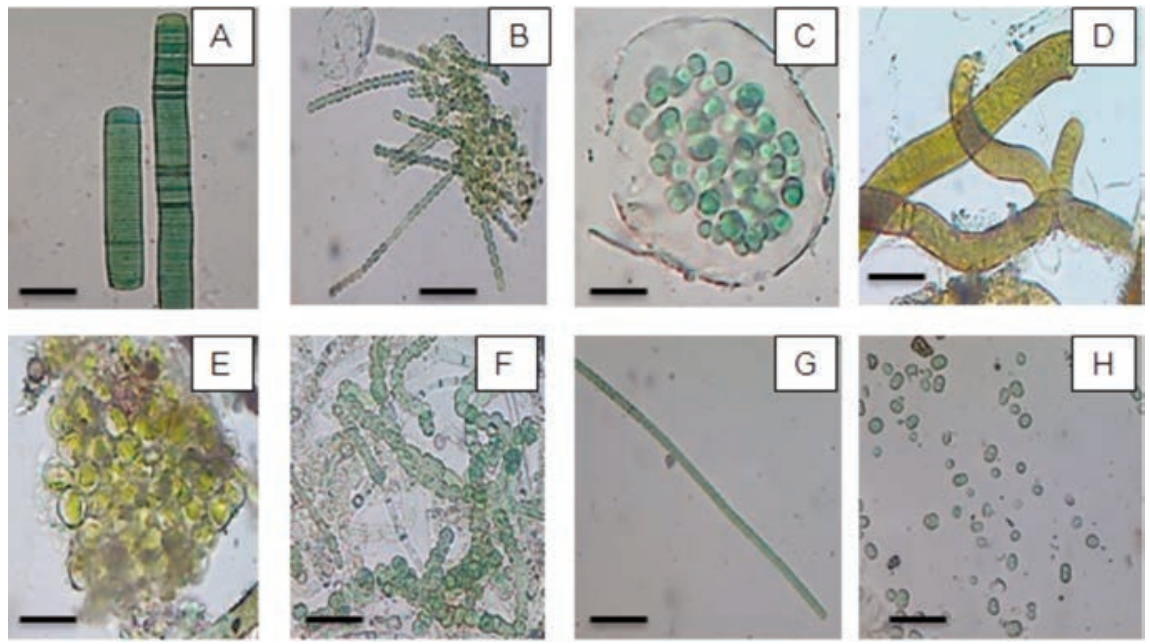

Figure 3. Cyanobacteria isolated from different historical monuments of Varanasi (A) Lyngbya sp., (B) Anabaena sp., (C) Nostoc sp., (D) Scytonema sp., (E) Aphanocapsa sp., (F) Westiellopsis sp., (G) Phormidium sp. and (H) Aphanothece sp. Scale bar $=10 \mu \mathrm{m}$. 


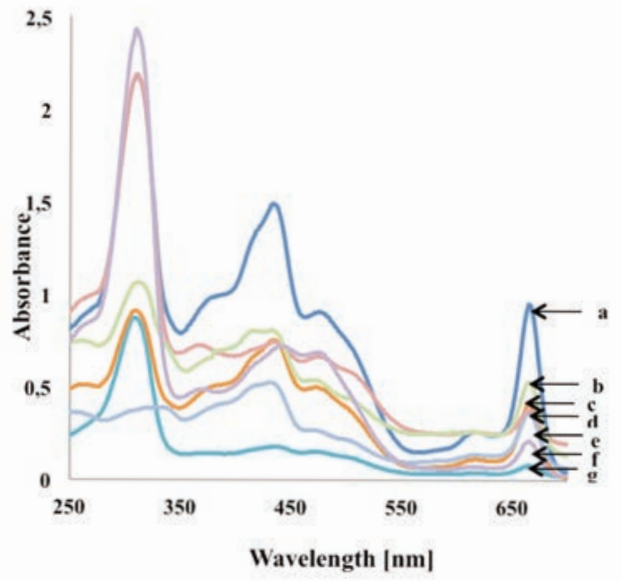

Figure 4. Absorption spectra of methanolic extracts of crust samples from different historical monuments of Varanasi, India (a) Ramnagar Fort, (b) Madhavrav's dharhara, (c) Brahaspati Temple, (d) Bharatmata Temple, (e) Sanskrit University, (f) Jalnigam's old tank and (g) Vishwanath Temple, BHU. All the experiments were repeated thrice with at least three replicates.

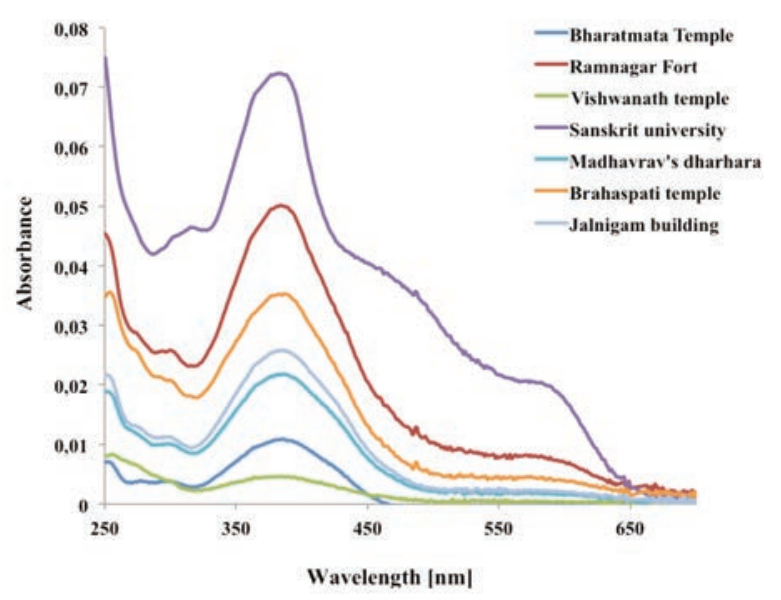

Figure 5. Absorption Spectra of scytonemin extracted from cyanobacterial samples collected from different historical monuments of Varanasi, India. All the experiments were repeated thrice with at least three replicates. exposure to the surface. The exposed roof top of the monuments, was mostly covered by dark brown coloured crust and composed primarily of Lyngbya sp. and Scytonema sp. whereas the walls were dominated by unicellular forms of cyanobacteria species like Aphanothece sp. and Aphanocapsa sp. Cyanobacteria are the dominant species colonizing on the sub aerial surfaces in warm temperate to tropical regions, ${ }^{28,29}$ as they have the capacity to tolerate high temperature, desiccation and can protect themselves from intense solar radiation. During summer months the temperature of surface of monuments reaches up to $55^{\circ} \mathrm{C}$, coupled with high light intensity, UV radiation and extreme dryness and cyanobacteria can withstand such extreme environment and survive in the surfaces of these monuments as blackishbrownish crust.

\section{Pigment profile}

Pigment profile of the crusts from the eight monuments of Varanasi is given in Figures 4 and 5. The absorption spectra of $90 \% \quad(\mathrm{v} / \mathrm{v})$ methanolic extract showed absorption at $665 \mathrm{~nm}$ due to chlorophyll-a, at $470 \mathrm{~nm}$ due to carotenoids and at $384 \pm 2$, 300 and $252 \mathrm{~nm}$ due to scytonemin. In all the crust samples scytontemin content (mg/gfw) was found to be quite prominent than the chlorophyll and carotenoids content, indicating its important role in photoprotection. Chlorophyll content ( $\mu \mathrm{g} / \mathrm{gfw}$ ) was found to be less than carotene content $(\mu \mathrm{g} / \mathrm{gfw})$ in all the samples (Figure 6) except in the crust collected from Bharatmata Temple and this might be due to the shadow effect of the nearby wall.

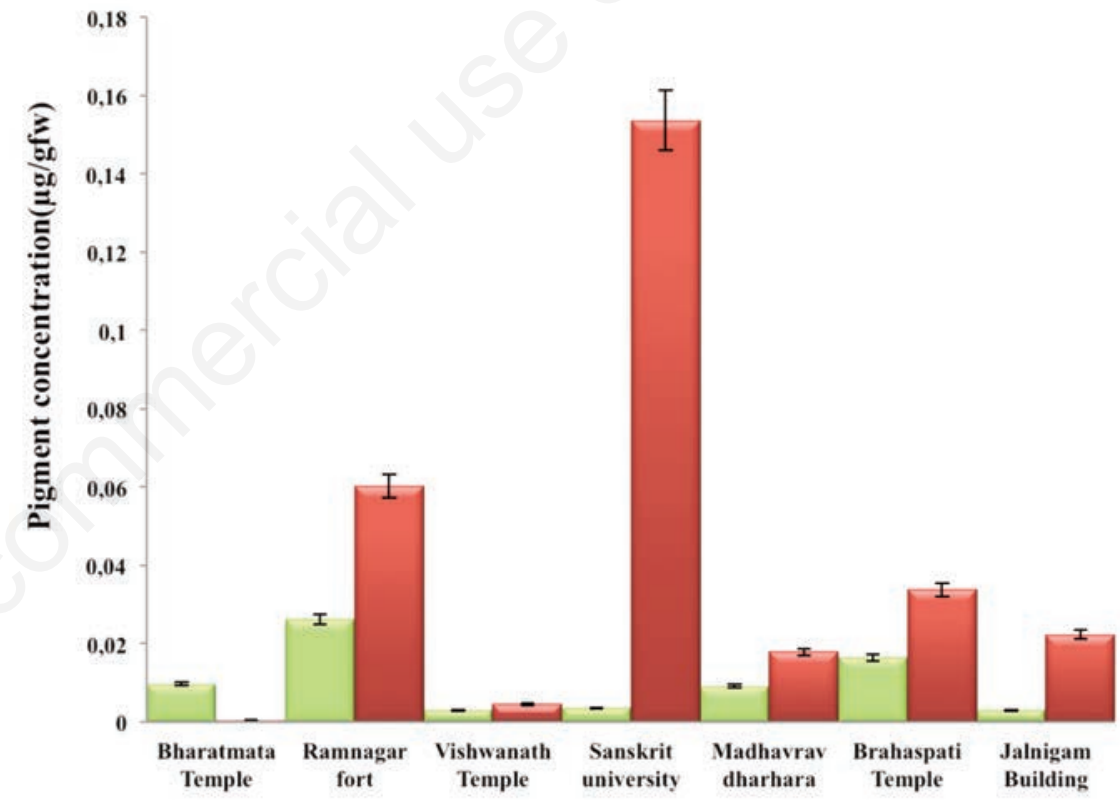

Collection sites of cyanobacterial crusts

Figure 6. Pigment analysis of cyanobacterial samples collected from different historical monuments of Varanasi, India. All the experiments were repeated thrice with at least three replicates. Bars represent \pm SD. Chlorophyll and total carotene contents are represented by green and red bars respectively.

Carotenoids are thought to protect cyanobacteria against photoxidative reaction and are also known for their antioxidant activity. ${ }^{30}$ In cyanobacteria carotenoids occur in outer cellular membrane as well as in thylakoid and during long-term exposure to high irradiance, higher ratios of carotenoids to chlorophyll-a have been reported in some species of cyanobacteria. ${ }^{31}$
Cyanobacteria which are exposed to intense solar radiation have also been found to contain one or more UV-absorbing compounds like extracellular sunscreen pigment scytonemin which acts as a photoprotectant against high solar irradiance. ${ }^{13}$ Since the terrestrial cyanobacteria colonising the surface of the monuments, survive for long period of quiescence and due to desiccation 


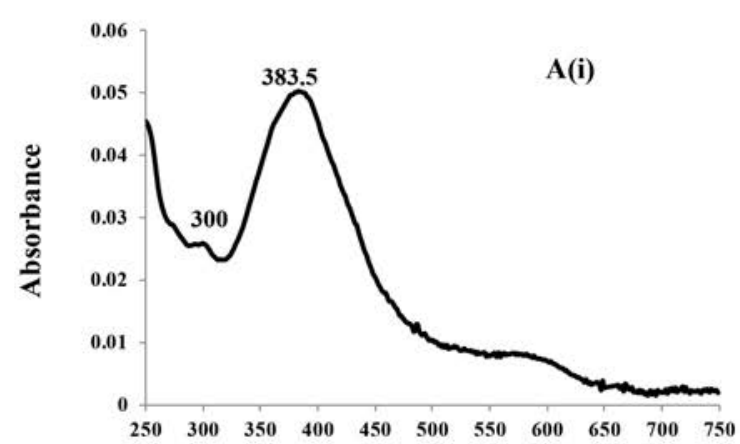

Wavelength $[\mathbf{n m}]$
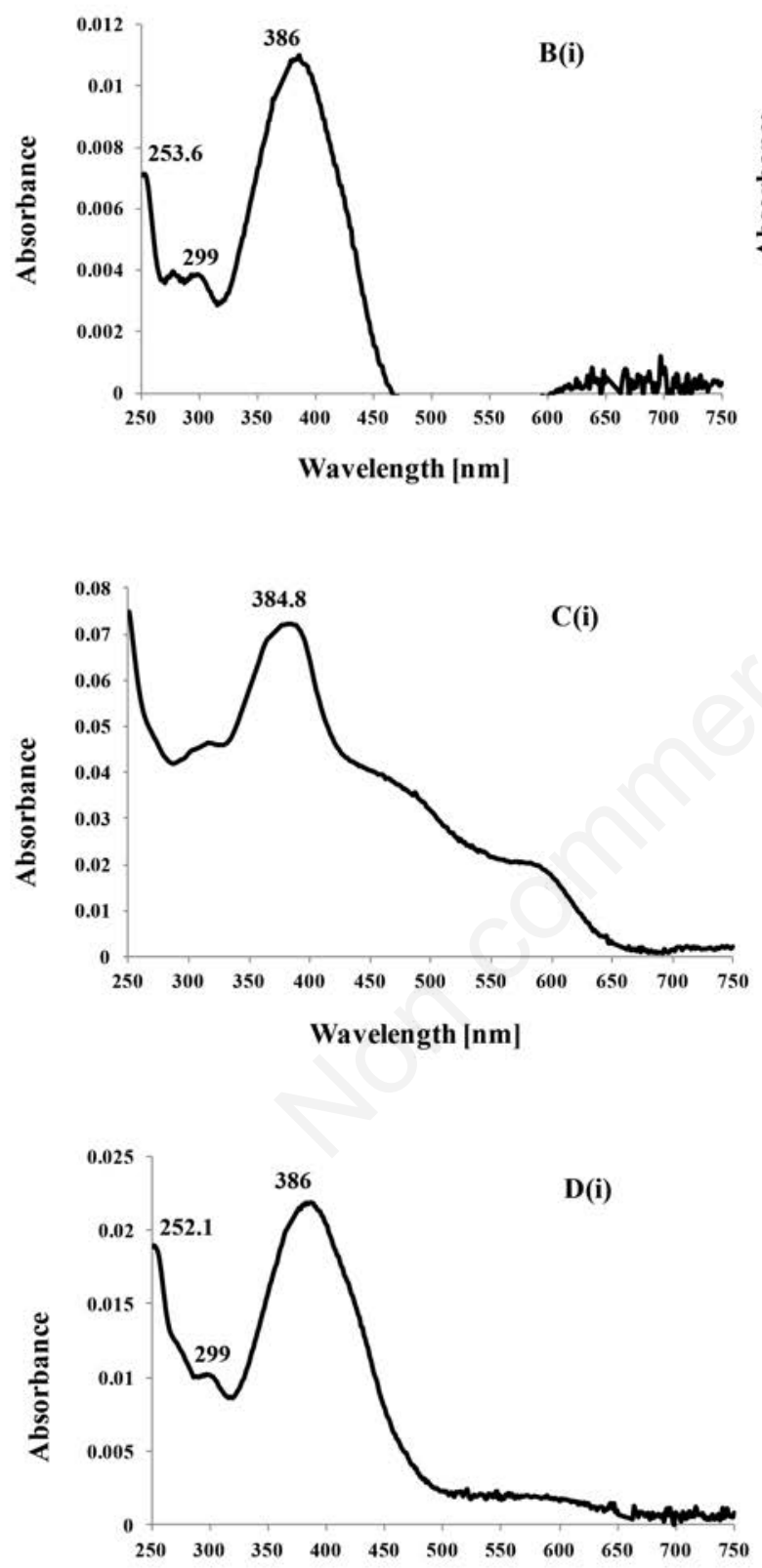

Wavelength $[\mathrm{nm}]$

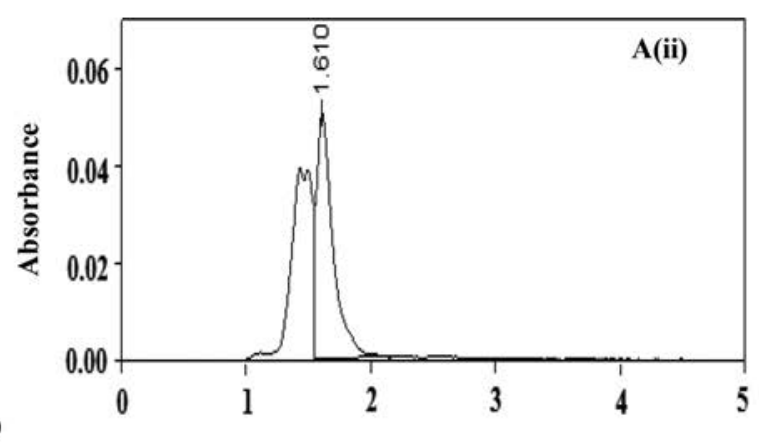

Retention time [min]
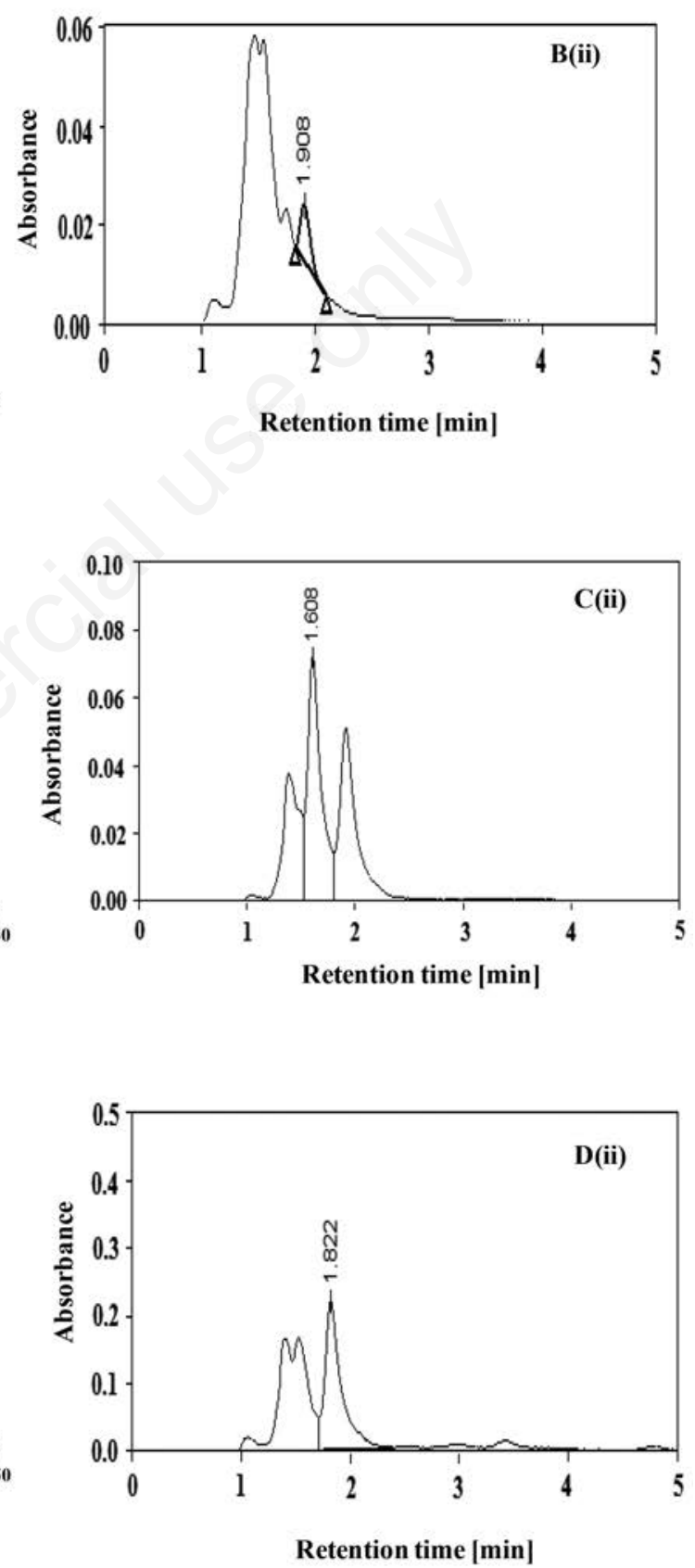

Figure 7. Absorption spectra of partially purified scytonemin (i) and its corresponding HPLC chromatograms (ii) from crust samples of (A) Bharatmata Temple, (B) Ramnagar Fort, (C) Vishwanath Temple, BHU and (D) Sanskrit University. All the experiments were repeated thrice with at least three replicates. 

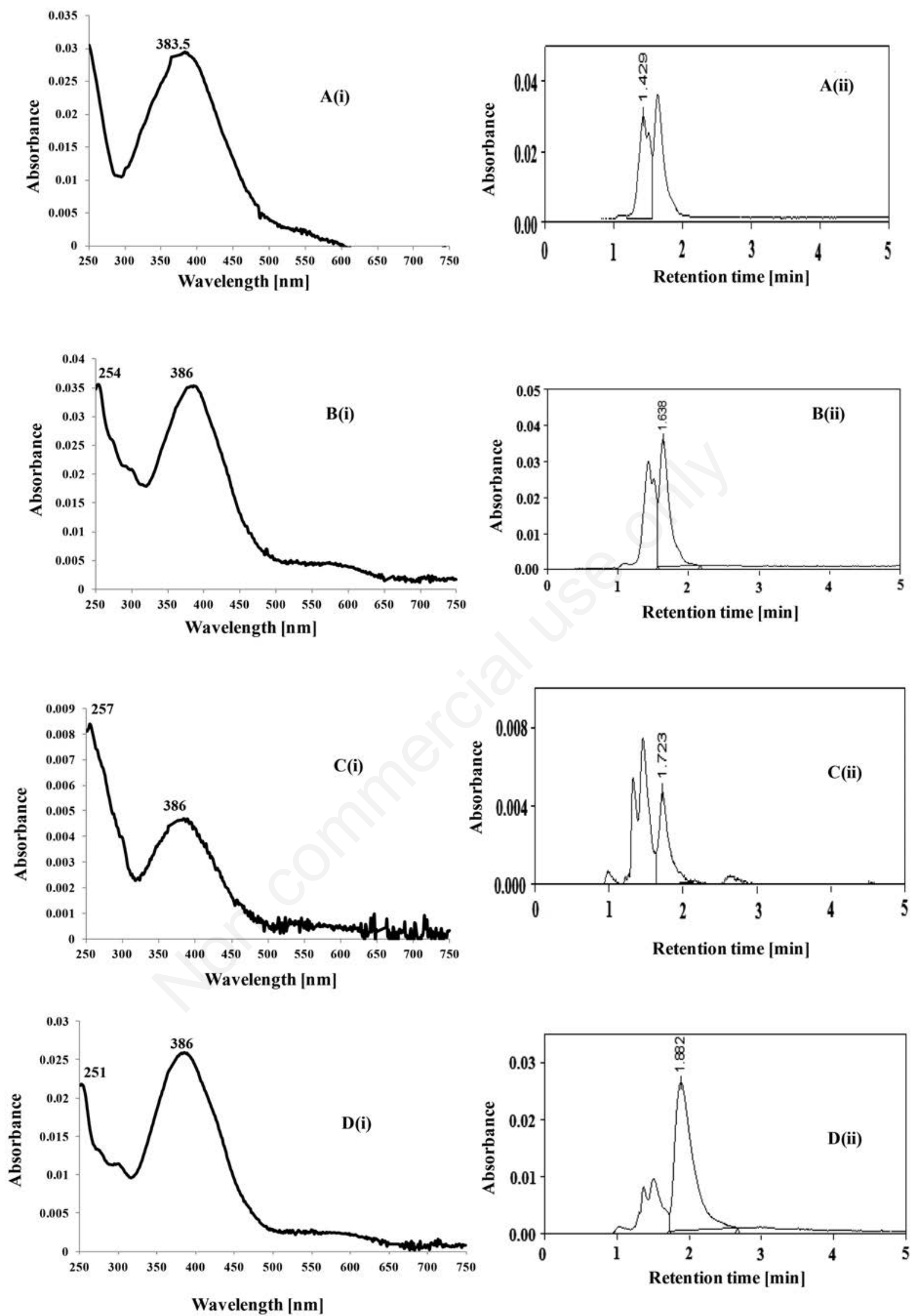

Figure 8. Absorption spectra of partially purified scytonemin (i) and its corresponding HPLC chromatograms (ii) from crust samples of (A) Madhavrav's Dharhara, (B) Brahaspati Temple (RT 1.63), (C) Brahaspati Temple (RT 1.73) and (D) Jalnigam's old tank. All the experiments were repeated thrice with at least three replicates. 
and exposure to solar radiation, they synthesize scytonemin as a mitigation strategy to reduce photo damage of their cells which play vital role for their survival.

\section{HPLC analysis and partial purifica- tion of scytonemin}

In the present study we made an attempt to partially purify scytonemin from the crusts. Scytonemin was found to be present in all of the crusts samples except in the crusts collected from Dhamek Stup, Sarnath. Scytonemin from the crust of the seven monuments shows a strong absorbance in the ultraviolet region of the spectrum with major peaks in the UV-A region (at $384 \pm 2 \mathrm{~nm}$ ), UV-B (at $300 \pm 2 \mathrm{~nm}$ ) and continue up to UV-C region (at $252 \pm 2$ $\mathrm{nm}$ ) (Figures 7 and 8). The cellular scytonemin content (mg/ gdw) was found to be maximum in the crust collected from Old building of Sanskrit University followed by crust collected from Ramnagar Fort and was found to be minimum in the crust collected from Vishwanath Temple, BHU (Figure 9).

The biosynthesis of scytonemin is greatly affected under different abiotic stress. ${ }^{32,33}$ Synthesis of scytonemin has been shown to be enhanced by high temperature, photo-oxidative stress and periodic desiccation stress. ${ }^{34}$ High culture temperature, strong illumination intensity, and lightdark cycle $(12: 12 \mathrm{~h})$, nitrogen deficiency, salinity were found to elevate the synthesis of the scytonemin. ${ }^{35-37}$ Osmotic stress and elevated UV-A exposure in combination with temperature or photooxidative stress induces the synthesis of scytonemin. ${ }^{32} \mathrm{UV}$ radiation plays a key role in promoting the synthesis of scytonemin. ${ }^{38}$ Overall, a number of environmental factors have been reported to enhance the synthesis of scytonemin, but the exact mechanisms that govern the production of scytonemin are yet to be elucidated.

\section{Discussion and Conclusions}

Cyanobacteria are possibly the most ancient photosynthetic microorganisms that have some mechanisms including synthesis of UV-absorbing pigment, scytonemin, to deal with the consequences of UV radiation in their natural habitats. We have reported 10 species of cyanobacteria from historical monuments of Varanasi, which constituted the major composition of crust. Sheathed cyanobacteria such as Lyngbya sp. and Scytonema sp were the dominant cyanobacterial taxa in all the monuments. Lyngbya sp. and Scytonema sp. have a gelatinous sheath that acts as a reservoir of water, where it is bound through strong molecular forces that allow cyanobacteria to colonize stone/rocks even during dry conditions. ${ }^{39}$ The sheath plays an important role in adhesion to the substratum. Sometimes thick sheaths may be pigmented such as in Gloeocapsa or Scytonema with intense colors, being the reflection of environmental adaptations at diverse ecological stages. Under low-nitrogen conditions, cyanobacteria can take on yellow-brown color as a result of reduction in chlorophyll and phycocyanin with an increase in carotenoids. Pigmentation may also change in response to environmental factors such as light quality, light intensity, temperature, nutrient availability and the age of cells. ${ }^{40}$ The cyanobacterial sheath has been suggested to be associated with cellular resistance against various environmental stresses and presence of UV-absorbing pigments, extrapolysaccharides (EPS) and water stress protein (Wsp) have been reported to be present in the cyanobacterial sheath of various genera. ${ }^{41}$ In the present study, the UVabsorbing pigment, scytonemin from cyanobacterial crusts was screened and partially purified through HPLC. Scytonemin occur in several species of cyanobacteria $^{42,43}$ and are induced by exposure to UVR and periodic desiccation. ${ }^{7,32}$ The incident UV-A radiation entering the cells may be reduced by approximately $90 \%$ because of the presence of scytonemin in the cyanobacterial sheaths. ${ }^{16,17}$ Nostoc flagelliforme containing UV-absorbing compounds showed photosynthetic insensitivity to solar UVR. ${ }^{44}$ Such studies reflect the involvement of UV-screening compounds as efficient protective mechanisms in cyanobacteria.

Scytonemin as well as MAAs considerably absorb radiation throughout the UV-A and UV-B regions. The protective effects of UV-absorbing compounds on diverse vital biological processes including photosynthetic carbon fixation, ${ }^{45}$ have been demonstrated in a wide range of organisms. ${ }^{45-47} \mathrm{In}$ $N$. flagelliforme the combination of compounds having complementary absorption maxima at $370 \mathrm{~nm}$, corresponding to in vivo absorption of scytonemin, ${ }^{26}$ and $312 / 335$ $\mathrm{nm}$, corresponding to MAAs, ${ }^{48}$ is very likely to induce the photosynthetic insensitivity to UVR. ${ }^{44}$ In addition to the mutual shading of cells in the multiserate filaments of $N$. flagelliforme, the predominant localization of scytonemin in the outer layer was likely to increase the protection of this organism from harmful UV-radiation. ${ }^{46,49}$

Our study reveals that most of the blackish brown crust appeared on exposed roof surfaces and composition of the microbial crust varies greatly according to different environmental condition and nature of the substratum. For example, Granite, with a very low $\mathrm{pH}$ and porosity represent an

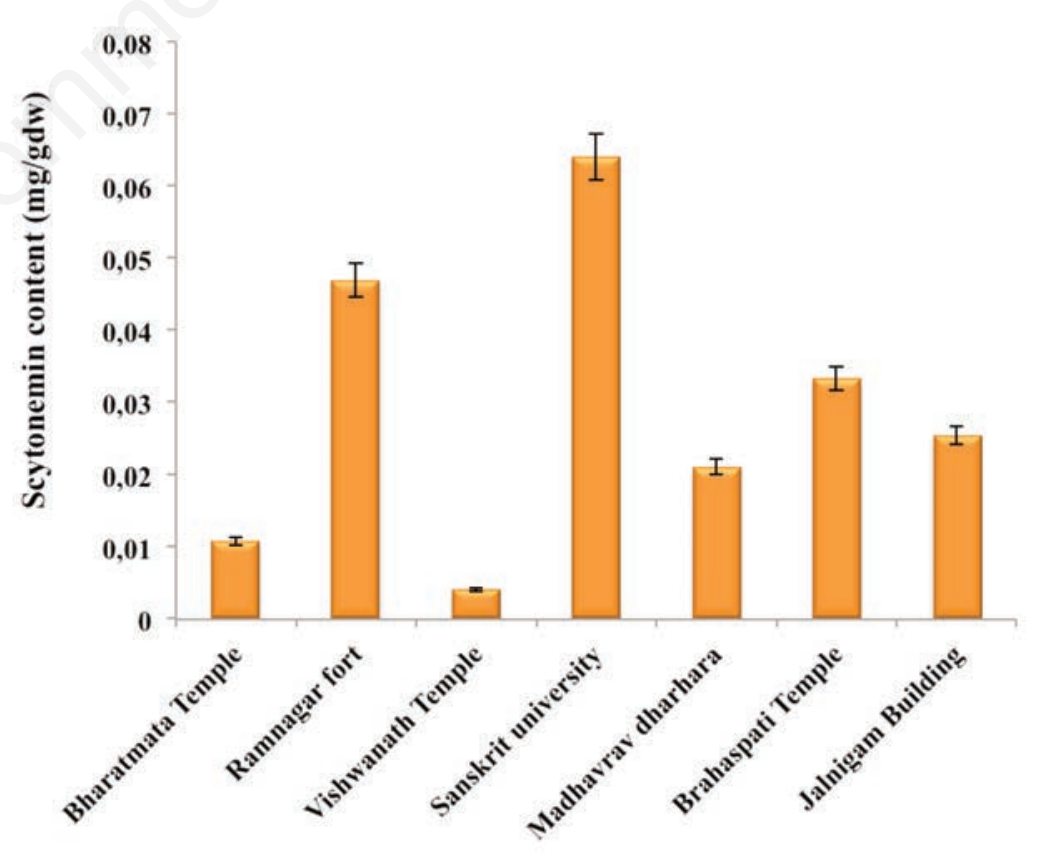

Sites of collection of cyanobacterial crusts

Figure 9. Scytonemin content of cyanobacterial samples collected from different historical monuments of Varanasi. All the experiments were repeated thrice with at least three replicates. Bars represent \pm SD. 
unfavorable substratum for cyanobacteria. ${ }^{52}$ The colonization of substratum such as stones is closely correlated with roughness, porosity, capillary water absorption and hygroscopicity which strongly influence the water availability for micro-organisms..$^{53-55}$ Environmental parameters such as temperature, solar radiation, water regime, climate, etc. play an important role in a successful colonization hence high number of taxa were found on a substratum does not necessarily imply high bioreceptivity of that substratum. In this study, we have selected monuments subjected to similar climatic conditions. However, the extent to which microclimatic parameters (orientation, permanent capillary humidity, exposure to shadow etc.) determine colonization is still not very clear. The microclimate determines the degree of colonization, the type of community and its specific composition. Monuments can create microclimatic differences between places that are very close. ${ }^{56}$

HPLC analyses of the photoprotective pigment extracted from cyanobacterial crust exhibited the existence of an UV absorbing compound, scytonemin, with absorption maxima at $384 \pm 2 \mathrm{~nm}$. Synthesis of scytonemin was found to be higher than carotene and chlorophyll in all the crust samples collected from different monuments indicating that the cyanobacteria can protect itself from harmful doses of UVR by inducing the synthesis of scytonemin as a cellular defence mechanism. Scytonemin has great potential in photoprotection and genome maintenance by minimizing the cellular damage from UV-induced ROS and thymine dimer formation. ${ }^{8,57}$ More studies are needed to understand the induction and protection mechanisms of this ecologically important scytonemin molecule in cyanobacteria under varying environmental stress including UV radiation.

\section{References}

1. Häder DP, Helbling EW, Williamson $\mathrm{CE}$, et al. Effects of UV radiation on aquatic ecosystems and interactions with climate change. Photochem Photobiol Sci 2011;10:242-60.

2. Weatherhead EC, Andersen SB. The search for signs of recovery of the ozone layer. Nature 2006;441:39-45.

3. Rastogi RP, Singh SP, Häder DP, Sinha RP. Detection of reactive oxygen species (ROS) by the oxidant-sensing probe $2^{\prime}, 7^{\prime}$-dichlorodihydrofluorescein diacetate in the cyanobacterium Anabaena variabilis PCC 7937. Biochem Biophys Res Commun 2010;397:603-7.
4. Vincent WF, Neale PJ. Mechanisms of UV damage to aquatic organisms. In: de Mora SJ, Demers S, Vernet M (Eds.), The effects of UV radiation on marine ecosystems. Cambridge: Cambridge University Press; 2000. pp 149-176.

5. Buma AGJ, De Boer MK, Boelen P. Depth distributions of DNA damage in Antarctic marine phyto and bacterioplankton exposed to summertime UV radiation. J Phycol 2001;37:200-8.

6. Peak MJ, Peak JG. Single-strand breaks induced in Bacillus subtilis DNA by ultraviolet light: action spectrum and properties. Photochem Photobiol 1982;35:675-80.

7. Sinha RP, Dautz M, Häder DP. A simple and efficient method for the quantitative analysis of thymine dimers in cyanobacteria, phytoplankton and macroalgae. Acta Protozool 2001;40:187-95.

8. Hargreaves A, Taiwo FA, Duggan O, et al. Near-ultraviolet photolysis of $\beta$ phenylpyruvic acid generates free radicals and results in DNA damage. J Photochem Photobiol B: Biol 2007;89:110-6.

9. Richa, Sinha RP, Häder DP. Physiological aspects of UV-excitation of DNA. Top Curr Chem 2015;356:20348.

10. Singh SP, Häder DP, Sinha RP. Cyanobacteria and ultraviolet radiation (UVR) stress: mitigation strategies. Ageing Res Rev 2010;9:79-90.

11. Rastogi RP, Kumari S, Richa, et al. Molecular characterization of hot spring cyanobacteria and evaluation of their photoprotective compounds. Can J Microbiol 2012;58:719-27.

12. Richa, Kannaujiya VK, Kumari S, et al. Effects of ultraviolet-B radiation on a hot-spring cyanobacterium Nostoc sp. strain HKAR-2. Acta Biol Indica 2013;2:265-76.

13. Rastogi RP, Sinha RP, Incharoensakdi A. Partial characterization, UV-induction and photoprotective function of sunscreen pigment, scytonemin from Rivularia sp. HKAR-4. Chemosphere 2013;93:1874-8.

14. Sinha RP, Klisch M, Vaishampayan A, et al. Biochemical and spectroscopic characterization of the cyanobacterium Lyngbya sp. inhabiting Mango (Mangifera indica) trees: presence of an ultraviolet-absorbing pigment, scytonemin. Acta Protozool 1999;38:291-8.

15. Garcia-Pichel F, Castenholz RW. Characterization and biological implication of scytonemin, a cyanobacterial sheath pigment. J Phycol 1991;27:395409.
16. Brenowitz S, Castenholz RW. Longterm effects of UV and visible irradiance on natural populations of a scytonemin-containing cyanobacterium (Calothrix sp.). FEMS Microbiol Ecol 1997;24:343-52.

17. Garcia-Pichel F, Sherry ND, Castenholz RW. Evidence for a UV sunscreen role of the extracellular pigment scytonemin in the terrestrial cyanobacterium Chlorogloeopsis sp. Photochem Photobiol 1992;56:17-23.

18. Matsui K, Nazifi E, Hirai Y, et al. The cyanobacterial UV-absorbing pigment scytonemin displays radicals scavenging activity. J Gen Appl Microbiol 2012;58:137-44.

19. Stevenson CS, Capper EA, Roshak AK. The identification and characterization of the marine natural product scytonemin as a novel antiproliferative pharmacophore. J Pharmacol Exp Ther 2002;303:858-66.

20. Stevenson CS, Capper EA, Roshak AK, et al. Scytonemin- a marine natural product inhibitor of kinases key in hyperproliferative inflammatory diseases. Inflamm Res 2002;51:112-4.

21. Rastogi RP, Sinha RP. Biotechnological and industrial significance of cyanobacterial secondary metabolites. Biotechnol Adv 2009;27:521-39.

22. Desikachary TV. Cyanophyta, Indian Council of Agricultural Research, New Delhi, India, 1959; 686.

23. Mackinney G. Absorption of light by chlorophyll solutions. J Biol Chem 1941;140:315-22.

24. Dere S, Günes T, Sivaci R. Spectrophotometric determination of chlorophyll - A, B and total carotenoid contents of some algae species using different solvents. Tr J Bot 1998;22:137.

25. Davis BH. Carotenoids. In: Goodwin TW, ed. Chemistry and biochemistry of plant pigment. New York, London; Academic press; 1976. pp 149-154.

26. Proteau PJ, Gerwick WH, Garcia-Pichel F, et al. The structure of scytonemin, an ultraviolet sunscreen pigment from the sheath of cyanobacteria. Experimentia 1993;49:825-9.

27. Rastogi RP, Incharoensakdi A. Characterization of UV-screening compounds, mycosporine-like amino acids and scytonemin in the cyanobacterium Lyngbya sp. CU2555. FEMS Microbiol Ecol 2014;87:244-56.

28. Ortega-Morales BO, Gaylarde CC, Englert GE, et al. Analysis of salt-containing biofilms on limestone buildings of the Mayan culture at Edzna, Mexico. Geomicrobiol 2005;22:261-8. 
29. Mandal S, Rath J. Algal colonization and its ecophysiology on the fine sculptures of terracotta monuments of Bishnupur, West Bengal, India. Int Biodeter Biodegr 2013;84:291-9.

30. Karsten U, Garcia-Pichel F. Carotenoids and mycosporine-like amino acid compounds in members of the genus Microcoleus (cyanobacteria): a chemosystematic study. Syst Appl Microbiol 1996;19:285-94.

31. Quesada A, Vincent WF. Strategies of adaptation by Antarctic cyanobacteria to ultraviolet radiation. Eur J Phycol 1997;32:335-42.

32. Dillon JG, Tatsumi CM, Tandingum PG, et al. Effect of environmental factors on the synthesis of scytonemin, a UV screening pigment, in a cyanobacterium (Chroococcidiopsis sp.). Arch Microbiol 2002;177:322-31.

33. Mushir S, Fatma T. Monitoring stress responses in cyanobacterial scytonemin-screening and characterization. Environ Technol 2012;33:153-7.

34. Fleming ED, Castenholz RW. Effects of periodic desiccation on the synthesis of the UV-screening compound, scytonemin, in cyanobacteria. Environ Microbiol 2007;9:1448-55.

35. Chen J, Zhao L, Xu J, et al. Determination of oxidize scytonemin in Nostoc commune Vauch cultured on different conditions by high performance liquid chromatography coupled with triple quadrupole mass spectrometry. J Appl Phycol 2013;25:1001-7.

36. Fleming ED, Castenholz RW. Effects of nitrogen source on the synthesis of the UV-screening compound, scytonemin, in the cyanobacterium Nostoc punctiforme PCC 73102. FEMS Microbiol Ecol 2008;63:301-8.

37. Rath J, Mandal S, Adhikary SP. Salinity induced synthesis of UV-screening compound scytonemin in the cyanobacterium Lyngbya aestuarii. J Photochem Photobiol B: Biol 2012;115:5-8.

38. Pentecost A. Field relationships between scytonemin density, growth and irradiance in cyanobacteria occurring in low illumination regimes. Micro
Ecol 1993;26:101-10.

39. Ortega-Calvo JJ, Hernandez-Marine M, Saiz-Jimenez C. Biodeterioration of building materials by cyanobacteria and algae. Int Biodeter 1991;28:165-85.

40. Macedo MF, Miller AZ, Dionísio A, et al. Biodiversity of cyanobacteria and green algae on monuments in the Mediterranean Basin: an overview. Microbiology 2009; 155:3476-90.

41. Hill DR, Peat A, Potts M. Biochemistry and structure of the glycan secreted by desiccation-tolerant Nostoc commune (Cyanobacteria). Protoplasma 1994;182:126-48.

42. Cockell CS, Knowland J. Ultraviolet radiation screening compounds. Biol Rev 1999;74:311-45.

43. Castenholz RW, Garcia-Pichel F. Cyanobacterial response to UV-radiation. In: Whitton BA, Potts M, Eds. The ecology of cyanobacteria: their diversity in time and space. Dordrecht: Kluwer Academic Publishers; 2000. pp 591611.

44. Gao K, Ye C. Photosynthetic insensitivity of the terrestrial cyanobacterium Nostoc flagelliforme to solar UV radiation while rehydrated or desiccated. J Phycol 2007;43:628-35.

45. Neale PJ, Banaszak AT, Jarriel CR. Ultraviolet sunscreens in Gymnodinium sanguineum (Dinophyceae): mycosporine-like amino acids protect against inhibition of photosynthesis. J Phycol 1998; 34:928-938.

46. Garcia-Pichel F, Wingard CE, Castenholz RW. Evidence regarding the UV sunscreen role of a mycosporinelike compound in the cyanobacterium Gloeocapsa sp.. Appl Environ Microbiol 1993; 59:170-176.

47. Klisch M, Sinha RP, Richter PR, Häder D-P. Mycosporine-like amino acids (MAAs) protect against UV-B-induced damage in Gyrodinium dorsum Kofoid. J Plant Physiol 2001; 158:1449-1454.

48. Garcia-Pichel F, Castenholz RW. Occurrence of UV-absorbing, mycosporine-like compounds among cyanobacterial isolates and an estimate of their screening capacity. Appl
Environ Microbiol 1993;59:163-9.

49. Ferroni L, Klisch M, Pancaldi S, Häder DP. Complementary UV-absorption of mycosporine-like amino acids and scytonemin is responsible for the UVinsensitivity of photosynthesis in Nostoc flagelliforme. Mar Drugs 2010;8:106-21.

50. Sinha RP, Häder DP. Photobiology and ecophysiology of rice field cyanobacteria. Photochem Photobiol 1996;64:88796.

51. Gröniger A, Sinha RP, Klisch M, et al. Photoprotective compounds in cyanobacteria, phytoplankton and macroalgae-a database. J Photochem Photobiol B: Biol 2000;58:115-22.

52. Ortega-Calvo JJ, Ariňo X, HernandezMarine, M. et al. Factors affecting the weathering and colonization of monuments by phototrophic microorganisms. Sci Total Environ 1995;167:329-41.

53. Urzì C, Realini M. Colour changes of Noto's calcareous sandstone as related to its colonisation by microorganisms. Int Biodeterior Biodegradation 1998;42:45-54.

54. Prieto B, Silva B. Estimation of the potential bioreceptivity of granitic rocks from their intrinsic properties. Int Biodeterior Biodegradation 2005;56: 206-15.

55. Miller AZ, Dionisio A, Macedo MF. Primary bioreceptivity: a comparative study of different Portuguese lithotypes. Int Biodeterior Biodegradation 2006;57:136-42.

56. Ortega-Calvo JJ, Sanchez-Castillo PM, Hernandez-Marine $\mathrm{M}$, et al. Isolation and characterization of epilithic chlorophyta and cyanobacteria from two Spanish cathedrals (Salamanca and Toledo). Nova Hedwigia 1993;57:23953.

57. Pathak J, Rajneesh R, Kannaujiya VK, et al. Diverse functions and applications of novel and unique cyanobacterial sheath pigment, scytonemin. In: Sinha RP, Richa, Eds. Biological sciences: innovations and dynamics. New Delhi: New India Publishing Agency; 2015. pp 237-262. 